\title{
LC-MS-MS aboard ship: tandem mass spectrometry in the search for phycotoxins and novel toxigenic plankton from the North Sea
}

\author{
Bernd Krock • Urban Tillmann • Uwe John • \\ Allan Cembella
}

Received: 31 March 2008/Revised: 30 May 2008/Accepted: 30 May 2008 /Published online: 28 June 2008

(C) Springer-Verlag 2008

\begin{abstract}
Phycotoxins produced by various species of toxigenic microalgae occurring in the plankton are a global threat to the security of seafood resources and the health of humans and coastal marine ecosystems. This has necessitated the development and application of advanced methods in liquid chromatography coupled to mass spectrometry (LC-MS) for monitoring of these compounds, particularly in plankton and shellfish. Most such chemical analyses are conducted in land-based laboratories on stored samples, and thus much information on the near real-time biogeographical distribution and dynamics of phycotoxins in the plankton is unavailable. To resolve this problem, we conducted shipboard analysis of a broad spectrum of phycotoxins collected directly from the water column on an oceanographic cruise along the North Sea coast of Scotland, Norway, and Denmark. We equipped the ship with a triple-quadrupole linear ion-trap hybrid LC-MS-MS system for detection and quantitative analysis of toxins, such as domoic acid, gymnodimine, spirolides, dinophysistoxins, okadaic acid, pectenotoxins, yessotoxins, and azaspiracids (AZAs). We focused particular attention on the detection of AZAs, a group of potent nitrogenous polyether toxins, because the culprit species associated with the occurrence of these toxins in shellfish has been controversial. Marine toxins were analyzed directly from size-fractionated plankton net tows (20 $\mu \mathrm{m}$ mesh size) and Niskin bottle samples from discrete depths, after rapid methanolic extraction but without any further clean-up. Almost all expected phycotoxins were
\end{abstract}

B. Krock $(\triangle) \cdot$ U. Tillmann $\cdot$ U. John $\cdot$ A. Cembella Alfred-Wegener-Institut für Polar- und Meeresforschung, Am Handelshafen 12,

27570 Bremerhaven, Germany

e-mail: bernd.krock@awi.de detected in North Sea plankton samples, with domoic acid and 20-methylspirolide $\mathrm{G}$ being most abundant. Although AZA was the least abundant of these toxins, the high sensitivity of the LC-MS-MS enabled detailed quantification, indicating that the highest amounts of AZA-1 were present in the southern Skagerrak in the 3-20 $\mu \mathrm{m}$ sizefraction. The direct on-board toxin measurements enabled isolation of plankton from stations with high AZA-1 levels and from the most suspicious size-fraction, i.e. most likely to contain the AZA-producer. A large number $(>100)$ of crude cultures were established by serial dilution and later screened for the presence of AZAs after several weeks growth. From one crude culture containing AZA, a small dinoflagellate was subsequently isolated and brought into pure culture. We have thus proved that even sophisticated mass spectrometers can be operated in ship laboratories without any limitation caused by vibrations of the ship's engine or by wave movement during heavy seas at wind forces up to nine Beaufort. On-board LC-MS-MS is a valuable method for near real-time analysis of phycotoxins in plankton for studies on bloom dynamics and the fate of toxins in the food web, and for characterization and isolation of putatively toxigenic organisms.

Keywords North Sea Plankton · Azaspiracids · AZA . Phycotoxins $\cdot$ Shellfish toxin $\cdot$ LC-MS-MS

\section{Introduction}

Tandem mass spectrometers, in particular hybrid instruments such as triple-quadrupole linear ion-trap systems, are regarded as highly sensitive and delicate equipment, requiring controlled laboratory conditions for reliable operation. Modern systems incorporating liquid chromatographs coupled with 
tandem mass spectrometers (LC-MS-MS) have relatively large orifices that require high pumping capacities. This pumping capacity is accomplished by differential pumping systems, including rotary vane and turbo-molecular pumps, the latter operating at several thousand rpm and thus having enormous torsional moment. Such systems are clearly not engineered for ship-board operation, where instruments may be subject to damage in transport and installation, vibration and erratic rocking motion when underway, unstable power supply, and corrosive effects of salt water and high humidity. Given these limitations, the traditional approach to LC-MS analysis of seawater and plankton matrices is to collect the samples at sea and to archive them by freezing, lyophilization, or solvent extraction for later laboratory analysis with advanced instrumentation. This procedure has a major drawback in that valuable in situ information on chemical composition is not available for optimization of the sampling programme or to conduct more detailed guided investigations - the strategy is essentially "blind". This temporal separation between sampling and chemical analysis has been a critical limitation of the wider application of LC-MS methodologies for field screening of phycotoxins in seawater and plankton matrices, because toxic plankton bloom are typically of relatively short duration (days to weeks) and are also spatially patchy.

Nevertheless, if technically feasible, operation of an onboard, highly sensitive LC-MS-MS system would be a very useful tool in field marine science and oceanography, particularly in studies of toxic bloom dynamics and toxin distribution in food webs where transient effects are critical to our understanding of the underlying processes. We are aware of one previous instance where an LC-MS system was deployed on a scientific cruise for shipboard analysis of phycotoxins [1], but this approach was a compromise between obtaining spectral information in near real-time while sacrificing sensitivity. The instrument was a small single-quadrupole mass spectrometer, operated in the selected-ion-monitoring (SIM) mode. This scan type is less sensitive than MS-MS modes, due to increased background noise and relatively low selectivity. Yet high sensitivity, especially for field measurements, is a key issue because secondary metabolites such as phycotoxins in seawater and plankton matrices are present only at very low concentrations (sub-nanomolar) and there are only limited means of sample concentration.

Here we report on the deployment of a triple quadrupolelinear ion trap hybrid LC-MS-MS system on a research vessel for a four week cruise on the North Sea. One major aim of this expedition was to investigate the potential use of advanced on-board LC-MS-MS systems for near real-time analysis of a wide variety of marine phycotoxins in plankton and seawater. We focused particularly on known phycotoxins, including domoic acid and lipophilic toxins, such as spirolides, dinophysistoxins, pectenotoxins, and yessotoxins associated with various shellfish toxin syndromes. We also intended to opportunistically exploit this on-board analytical capability to determine the hitherto unknown or unconfirmed identity of toxin producing plankton, such as the source of azaspiracids (AZAs) (Fig. 1), a group of potent nitrogen-containing macrocyclic polyether toxins first found in shellfish.

The first azaspiracid poisoning (AZP) was that of eight people in the Netherlands who became ill in November 1995 after consumption of mussels from the Irish west coast [2]. Symptoms of the affected persons-nausea, vomiting, severe diarrhoea, and stomach cramps-were typical of diarrheic shellfish poisoning (DSP), and, indeed, at first the toxicity was erroneously associated with this syndrome. However, the only DSP toxins present in the mussels were okadaic acid and dinophysistoxin-2 and at very low concentrations, which could not explain the severity of the human poisonings.

Several years after the initial poisoning incident, the lipophilic macrocyclic polyether azaspiracid-1 (AZA-1) was finally isolated from shellfish and structurally elucidated as the causative compound [3]. Other structural variants of AZA-1 have been isolated from shellfish and characterized, and 24 AZAs are now known [4]. The toxins associated with AZP are not restricted to Ireland; AZAcontaminated mussels have also been found on the English east coast and on the Norwegian west coast [5]. Other cases of human poisoning from the consumption of mussels in Ireland, France, and Italy have now been unambiguously attributed to AZP [6]. Nevertheless, the ultimate source of AZP remained elusive. The heterotrophic dinoflagellate Protoperidinium crassipes has been proposed as the causative organism [7], but this was somewhat unexpected because thus far only autotrophic plankton have proven to be producers of polyether phycotoxins [8]. Recently the Irish Marine Institute reported that there was no correlation between occurrence of AZAs in shellfish and blooms of P. crassipes during a four year monitoring period along the Irish coast (2002 to 2006) [9].

Plankton material from the water column along the North Sea coast was harvested by size-fractionation of plankton net tows and from Niskin bottle samples. Plankton fractions were extracted for direct on-board analysis of a broad spectrum of phycotoxins, including AZA, to determine the biogeographical distribution and to identify the AZA-producer(s). Our application demonstrates for the first time the feasibility, robustness, and efficacy of on-board direct measurements of phycotoxins by use of highly sensitive triple-quadrupole linear ion-trap LC-MS-MS. As illustrative of the more general application of on-board LC-MS-MS to such toxin studies, we also discovered a link between AZAs and an associated toxic planktonic organism. 
Fig. 1 Chemical structures of the different classes of phycotoxins

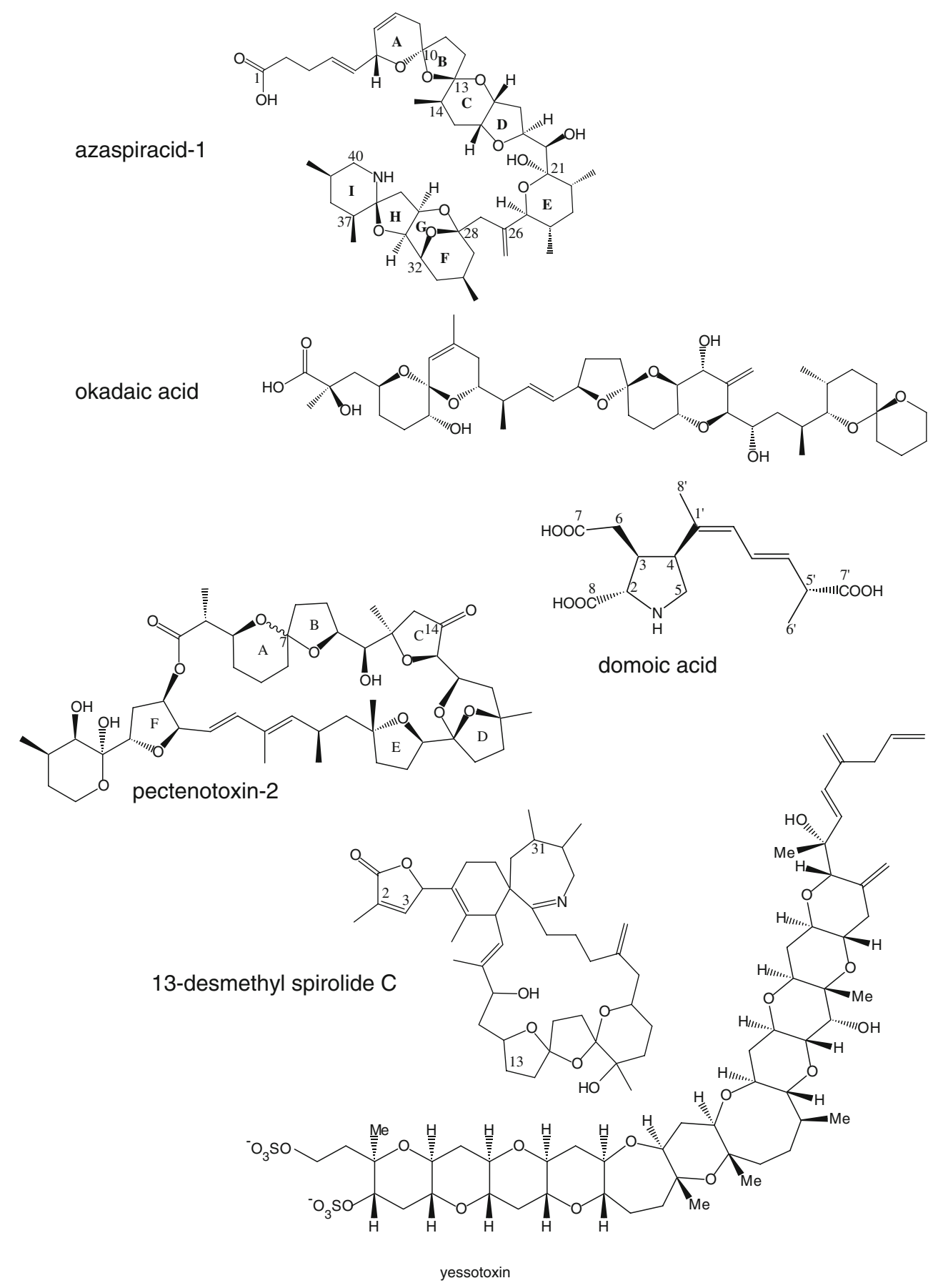

\section{Materials and methods}

Plankton collection and size-fractionation

Plankton samples were collected during the FS Poseidon 352 (ship dimensions: length $60.8 \mathrm{~m}$, width $11.4 \mathrm{~m}, 1049$ gross registered tons) cruise in the North Sea from 10th June to 4th July 2007 at stations along the Scottish east coast and on the south coast of Norway and the north coast of Denmark in the Skagerrak (Fig. 2). Vertical net tows were conducted at each station through the upper $20 \mathrm{~m}$ of the water column with a $20 \mu \mathrm{m}$-mesh plankton net. Net tow concentrates were adjusted with filtered seawater to a volume of $850 \mathrm{~mL}$. A $50 \mathrm{~mL}$ sub-sample was removed for microscopic analysis of plankton and the remainder was sequentially filtered through Nitex mesh of 200, 50, and $20 \mu \mathrm{m}$.

Discrete seawater samples were collected in Niskin entrapment bottles mounted on an automatically triggered rosette sampler at $3 \mathrm{~m}$ and $10 \mathrm{~m}$ depth. Seawater was passed through Nitex gauze of $20-\mu \mathrm{m}$ mesh-size and $1 \mathrm{~L}$ of each filtrate was then filtered through polycarbonate filters 
Fig. 2 Geographical locations of the sampling stations during the Poseidon 352 expedition in the North Sea

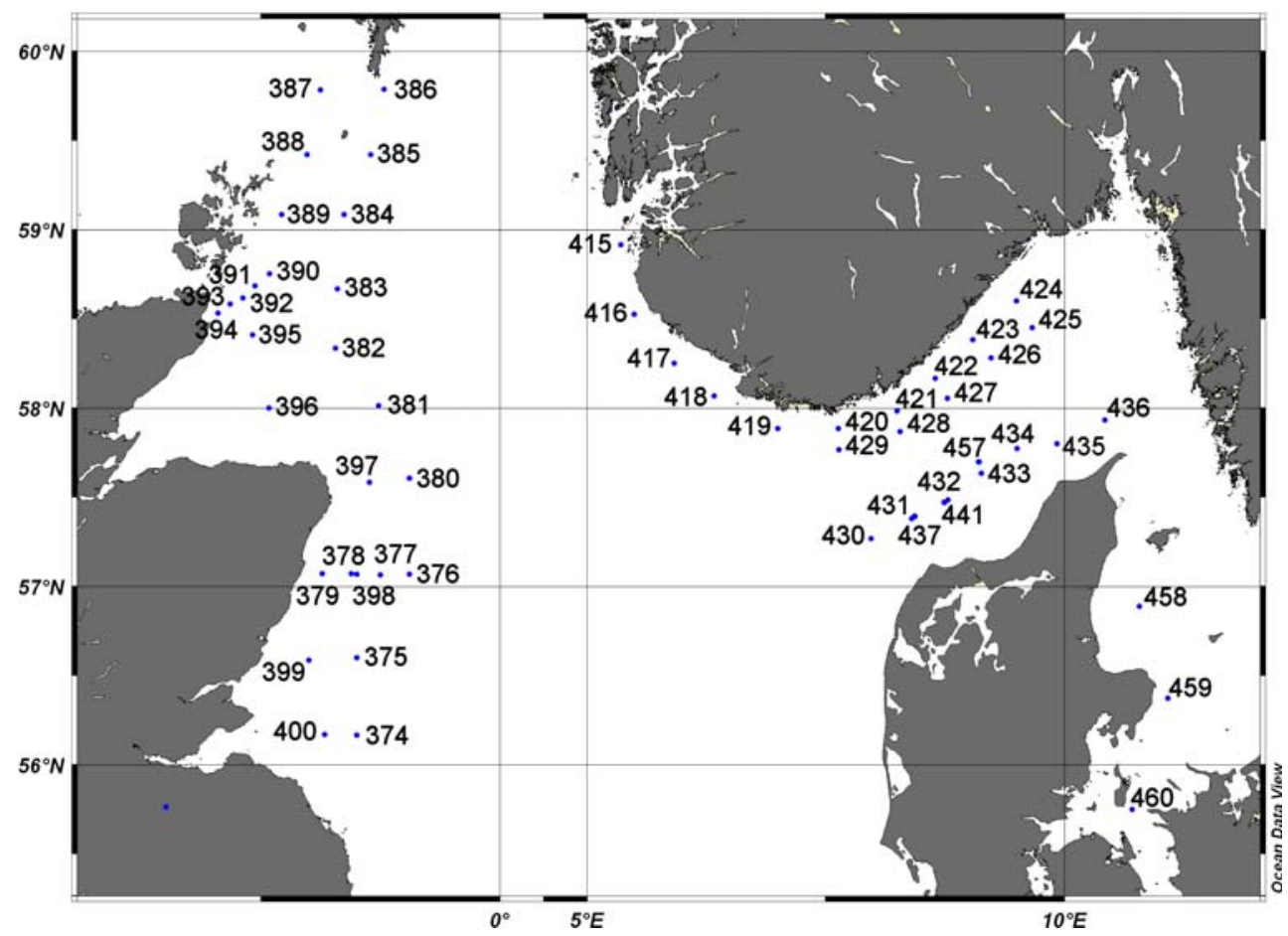

(25 mm diameter, Millipore) with $3 \mu \mathrm{m}$ pore-size. Filters were stored in 50-mL centrifuge tubes (Sarstedt, Nümbrecht, Germany) until analysis.

\section{Toxin extraction}

The cell pellets from the plankton net tows were harvested by centrifugation $\left(3,220 \times \mathrm{g}, 15 \mathrm{~min}\right.$ at $\left.4{ }^{\circ} \mathrm{C}\right)$, suspended in $500 \mu \mathrm{L}$ methanol, and subsequently transferred to a FastPrep tube containing 0.9 g lysing matrix D (Thermo Savant, Illkirch, France). The samples were homogenized by reciprocal shaking at maximum speed $\left(6.5 \mathrm{~m} \mathrm{~s}^{-1}\right)$ for $45 \mathrm{~s}$ in a Bio101 FastPrep instrument (Thermo Savant). After homogenization, samples were centrifuged (Eppendorf $5415 \mathrm{R}$, Hamburg, Germany) at $16,100 \times \mathrm{g}$ at $4{ }^{\circ} \mathrm{C}$ for $15 \mathrm{~min}$. The supernatant $(400 \mu \mathrm{L})$ was transferred to a spin-filter (pore-size $0.45 \mu \mathrm{m}$; Millipore Ultrafree, Eschborn, Germany) and centrifuged for $30 \mathrm{~s}$ at $800 \times \mathrm{g}$. The filtrate was transferred to an autosampler vial and analyzed by LC-MS-MS. Polycarbonate filters were repeatedly rinsed with $1 \mathrm{~mL}$ methanol until complete decolouration of the filters. The methanolic extract was filtered through spin-filters as described above.

Analytical reagents and standards

Water was deionized and purified (Milli-Q; Millipore) to $18 \mathrm{M} \Omega \mathrm{cm}^{-1}$ quality or better. Formic acid $(90 \%$, p.a.), acetic acid (p.a.), and ammonium formate (p.a.) were purchased from Merck (Darmstadt, Germany). The solvents methanol and acetonitrile were high-performance liquid chromatography (HPLC) grade (Merck).

A reference solution of AZA-1 and a mussel extract containing AZA-1, AZA-2, and AZA-3 were kindly donated by Philipp Hess, Marine Institute, Galway, Ireland.

On-board installation of the LC-MS-MS system

The complete LC-MS-MS system was placed on a bench in the rear dry laboratory of the Poseidon and lashed with retaining belts to fix the instrument. Ship electricity was accessed directly without further modification for voltage spikes or surge protection. Compressed air was supplied by the ship engine and purified with a charcoal filter (Option Carbon Absorber P/N 159.003678; Parker Filtration and Separation, Etten-Leur, The Netherlands) for a nitrogen generator. A N2-22 nitrogen generator (Parker Balston Analytical Gas Systems, Maidstone, UK) delivered nitrogen at 7 bar $\left(99.5 \%\right.$ purity at a flow rate of $\left.19 \mathrm{~L} \mathrm{~min}^{-1}\right)$.

Lipophilic toxin measurement of field samples by LC-MS-MS

Mass spectral experiments were performed on an ABISciex 4000 Q Trap triple-quadrupole mass spectrometer (Applied Biosystems, Darmstadt, Germany) equipped with a Turbo $\mathrm{V}$ ion source coupled to an Agilent (Waldbronn, Germany) 1100 LC liquid chromatograph which included a solvent reservoir, in-line degasser (G1379A), binary pump (G1311A), refrigerated autosampler (G1329A/G1330B), and temperature-controlled column oven (G1316A). 
Table 1 Mass spectrometric parameters used for the multi phycotoxin method

\begin{tabular}{llll}
\hline & $\begin{array}{l}\text { Period } 1 \\
(0-8.75 \mathrm{~min})\end{array}$ & $\begin{array}{l}\text { Period } 2 \\
(8.75-11.2 \mathrm{~min})\end{array}$ & $\begin{array}{l}\text { Period 3 } \\
(11.2-18.0 \mathrm{~min})\end{array}$ \\
\hline Curtain gas & $20 \mathrm{psi}$ & $10 \mathrm{psi}$ & $10 \mathrm{psi}$ \\
CAD & Medium & Medium & Medium \\
Ion-spray voltage & $5500 \mathrm{~V}$ & $5500 \mathrm{~V}$ & $5500 \mathrm{~V}$ \\
Temperature & $275^{\circ} \mathrm{C}$ & Ambient & Ambient \\
Nebulizer gas & $50 \mathrm{psi}$ & 10 psi & 10 psi \\
Auxiliary gas & $50 \mathrm{psi}$ & Off & Off \\
Interface heater & On & On & On \\
Declustering potential & $50 \mathrm{~V}$ & $50 \mathrm{~V}$ & $50 \mathrm{~V}$ \\
Entrance potential & $10 \mathrm{~V}$ & $10 \mathrm{~V}$ & $10 \mathrm{~V}$ \\
Exit potential & $15 \mathrm{~V}$ & $15 \mathrm{~V}$ & $15 \mathrm{~V}$ \\
MRM transitions (collision energy, V) & $312 \rightarrow 161(30)$ & $508 \rightarrow 490(40)$ & $822 \rightarrow 223(55)$ \\
& $312 \rightarrow 266(20)$ & $692 \rightarrow 164(55)$ & $836 \rightarrow 237(55)$ \\
& & $692 \rightarrow 150(55)$ & $946 \rightarrow 223(55)$ \\
& & $694 \rightarrow 164(55)$ & $874 \rightarrow 213(55)$ \\
& & $694 \rightarrow 150(55)$ & $892 \rightarrow 213(55)$ \\
& & $706 \rightarrow 164(55)$ & $894 \rightarrow 213(55)$ \\
& & $708 \rightarrow 164(55)$ & $842 \rightarrow 824(55)$ \\
& & & $1160 \rightarrow 965(55)$
\end{tabular}

After injection of $5 \mu \mathrm{L}$ of sample, separation of lipophilic toxins was performed by reversed-phase chromatography on a $\mathrm{C}_{8}$ phase. The analytical column $(50 \times 2 \mathrm{~mm})$ was packed with 3- $\mu$ m Hypersil BDS $120 \AA$ (Phenomenex, Aschaffenburg, Germany) and maintained at $20{ }^{\circ} \mathrm{C}$. The flow rate was $0.2 \mathrm{~mL} \mathrm{~min}{ }^{-1}$ and gradient elution was performed with two eluents, where eluent A was water and eluent B was acetonitrile-water $(95: 5 \mathrm{v} / \mathrm{v})$, both containing $2.0 \mathrm{mmol} \mathrm{L}^{-1}$ ammonium formate and $50 \mathrm{mmol} \mathrm{L}^{-1}$ formic acid. Initial conditions were $12 \mathrm{~min}$ column equilibration with $5 \% \mathrm{~B}$, followed by a linear gradient to $100 \% \mathrm{~B}$ in $10 \mathrm{~min}$ and isocratic elution until $15 \mathrm{~min}$ with $100 \% \mathrm{~B}$. The system was then returned to initial conditions until $18 \mathrm{~min}$ (total run time: $30 \mathrm{~min}$ ).

The chromatographic run was divided into three periods:

1) $0-8.75 \mathrm{~min}$ for domoic acid,

2) 8.75-11.20 min for gymnodimine and spirolides, and

3) 11.20-18 min for okadaic acid, dinophysistoxins, pectenotoxins, yessotoxin, and azaspiracid.

Measurements were carried out in positive-ion mode by multiple reaction monitoring (MRM) experiments. Mass spectrometric parameters are summarized in Table 1. Dwell times of 100-200 ms were used for each transition.

\section{Results and discussion}

Despite the calculated risk to the equipment and without precedent for ship-board operation, we report the successful and trouble-free functioning of the triple quadrupole linear ion-trap hybrid mass spectrometer under sea-going con-
Table 2 Mass transitions and retention times of toxins monitored on board

\begin{tabular}{|c|c|c|}
\hline Toxin $^{\mathrm{a}}$ & $\begin{array}{l}\text { Mass } \\
\text { transition } \\
(\mathrm{m} / \mathrm{z})\end{array}$ & $\begin{array}{l}\text { Retention } \\
\text { time } \\
(\mathrm{min})\end{array}$ \\
\hline Domoic acid & $312 \rightarrow 266 ; 312 \rightarrow 161$ & 7.58 \\
\hline Gymnodimine & $508 \rightarrow 490$ & 9.83 \\
\hline Spirolide A & $692 \rightarrow 150$ & \\
\hline Spirolide B & $694 \rightarrow 150$ & \\
\hline 13-Desmethylspirolide C & $692 \rightarrow 164$ & 10.42 \\
\hline Spirolide G & $692 \rightarrow 164$ & \\
\hline 13-Desmethylspirolide D & $694 \rightarrow 164$ & \\
\hline Spirolide C & $706 \rightarrow 164$ & \\
\hline 20-Methylspirolide G & $706 \rightarrow 164$ & 10.72 \\
\hline Okadaic acid & $822 \rightarrow 223$ & 11.85 \\
\hline DTX-1 & $836 \rightarrow 237$ & 12.83 \\
\hline DTX-2 & $822 \rightarrow 223$ & 12.15 \\
\hline PTX-1 & $892 \rightarrow 213$ & 11.33 \\
\hline PTX-2 & $876 \rightarrow 213$ & 12.40 \\
\hline PTX-2sa & $894 \rightarrow 213$ & 11.93 \\
\hline PTX-4 & $892 \rightarrow 213$ & \\
\hline PTX-8 & $892 \rightarrow 213$ & \\
\hline PTX-11 & $892 \rightarrow 213$ & 12.12 \\
\hline PTX-12 & $874 \rightarrow 213$ & 12.59 \\
\hline PTX-13 & $892 \rightarrow 213$ & 11.96 \\
\hline PTX-14 & $874 \rightarrow 213$ & \\
\hline AZA-1 & $842 \rightarrow 824$ & 13.88 \\
\hline YTX & $1160 \rightarrow 965$ & 12.45 \\
\hline
\end{tabular}

${ }^{\mathrm{a}} \mathrm{DTX}=$ dinophysistoxin, OA-d8 $=$ okadaic acid $\mathrm{C}_{8}$ diol ester, $\mathrm{PTX}=$ pectenotoxin, $\mathrm{sa}=$ seco acid, $\mathrm{AZA}=$ azaspiracid, $\mathrm{YTX}=$ yessotoxin 
Table 3 Limits of detection (LOD, $S / N=3$ ), and minimum and maximum amounts of phycotoxins found in North Sea plankton samples

\begin{tabular}{llll}
\hline Toxin $^{\mathrm{a}}$ & $\begin{array}{l}\text { LOD } \\
(\mathrm{ng} / \mathrm{NT})\end{array}$ & $\begin{array}{l}\text { Min } \\
(\mathrm{ng} / \mathrm{NT})\end{array}$ & $\begin{array}{l}\text { Max } \\
(\mathrm{ng} / \mathrm{NT})\end{array}$ \\
\hline Domoic acid & 0.3 & 0.5 & 12,800 \\
13-Desmethylspirolide C & 0.015 & n.d. & 3,670 \\
20-Methylspirolide G & 0.07 & n.d. & 83 \\
Okadaic acid & 0.085 & 0.085 & 41.7 \\
DTX-1 & 0.15 & n.d. & 24.4 \\
DTX-2 & 0.15 & n.d. & 60.9 \\
PTX-2 & 0.25 & n.d. & 207 \\
PTX-2 seco acid & 0.07 & n.d. & 69.8 \\
PTX-11 & 0.13 & n.d. & 11 \\
YTX & 0.05 & n.d & 56 \\
AZA-1 & 0.015 & n.d & 6.7 \\
\hline
\end{tabular}

${ }^{\mathrm{a}}$ DTX $=$ dinophysistoxin; PTX $=$ pectenotoxin; YTX $=$ yessotoxin; $\mathrm{AZA}=$ azaspiracid

ditions. The system proved to be both robust and absolutely stable throughout the cruise. Several power-supply failures, vibration caused by the ship engines, and heavy seas (3$6 \mathrm{~m}$ waves) with wind force of up to Beaufort 9 had no effect on the performance of the instrument, which was continuously operated throughout the entire expedition. Even after four weeks of ship-board operation, followed by venting and transport to the institute, no tuning or mass calibration were necessary.
During the Poseidon 352 expedition, 423 samples at 48 geographical stations were analyzed for phycotoxins. An overview of the toxins surveyed by the LC-MS-MS method, including their mass transitions and retention times, is presented in Table 2. The range of phycotoxins detected in plankton net tows is given in Table 3. Domoic acid, a rare neurotoxic amino acid produced by the pennate diatom Pseudo-nitzschia spp. [10] and associated with amnesic shellfish poisoning (ASP) in humans, was found at all stations over a wide concentration range from 0.5 to $12,800 \mathrm{ng}$ per plankton net tow (approximately $2500 \mathrm{~L}$ of seawater filtered). The macrocyclic imine gymnodimine and related analogues, which occur primarily in temperate waters around New Zealand [11] but also the Mediterranean [12], in association with the dinoflagellate Karenia brevesulcata, were not detected. The related group of macrocyclic imine toxins known as spirolides and originating from the dinoflagellate Alexandrium ostenfeldii was detected at some stations. Cultured isolates of $A$. ostenfeldii may produces a diversity of spirolides [13, 14], but only 20-methylspirolide $\mathrm{G}$ and to a lesser extent 13-desmethylspirolide $\mathrm{C}$ were found in the North Sea field plankton samples. Somewhat surprisingly, spirolides A, B, C, D, and $\mathrm{G}$ were completely absent. Several species of the genus are believed to produce the dinophysistoxins (DTXs) [15], and okadaic acid and pectenotoxins (PTXs) [16, 17], believed to originate from the planktonic dinoflagellate genus Dinoph$y$ sis. These toxins are often collectively (and erroneously in the case of pectenotoxins) associated with the diarrheic
Fig. 3 LC-MS-MS chromatogram obtained from the 20-50 $\mu \mathrm{m}$ plankton fraction of a net tow collected at St 376 east of Aberdeen, Scotland

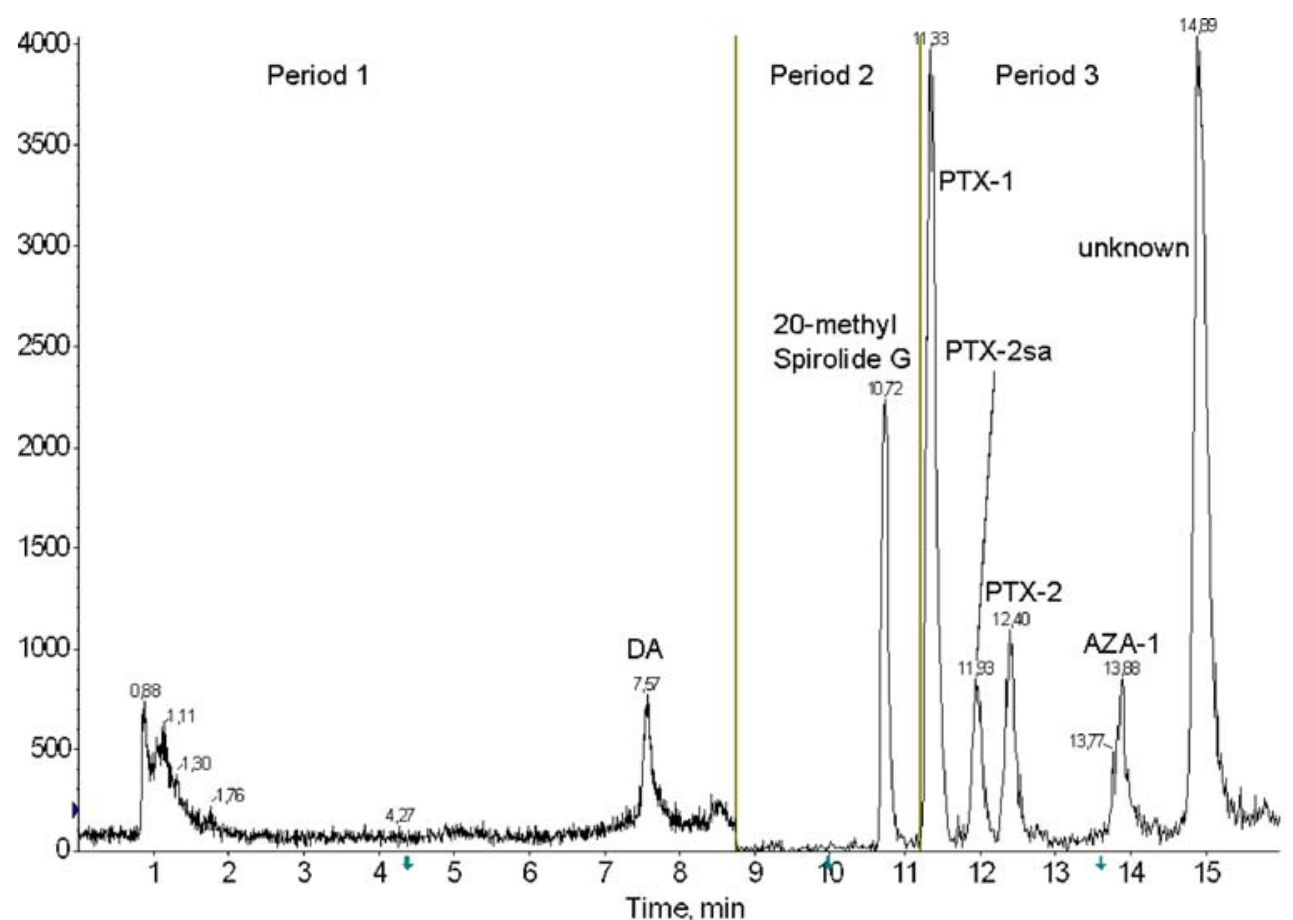


shellfish poisoning (DSP) syndrome. In our North Sea samples, PTX-2 was the most abundant variant among members of the PTX-group, whereas ratios of okadaic acid to DTX-1 and DTX-2 varied significantly among sampling stations. Yessotoxin and azaspiracid-1 were the least abundant of the detected phycotoxins. A typical chromatogram from a net tow size-fraction $(50-20 \mu \mathrm{m})$ is shown in Fig. 3.

The azaspiracid AZA-1 was detected in plankton net tows at all sampling stations in the North Sea (Fig. 2). On the Scottish coast, however, AZA-1 concentrations north of $58^{\circ}$ latitude were very low and abundance was generally higher at sampling stations closer to the shore. The AZA-1 levels were particularly high at two stations St 374 and 398 on the Scottish coast. Interestingly, the highest abundances were found in the $50 \mu \mathrm{m}$ fraction, whereas at all other stations AZA-1 was more evenly distributed among the three size-fractions. Although several Protoperidinium species were present in the 50-200 $\mu \mathrm{m}$ size-fractions, albeit at relatively low cell numbers, $P$. crassipes (Kofoid) Balech, the previously reported source of AZA, was very rare.

Crude on-board cultures initiated by serial dilution from natural plankton samples (Krock et al. submitted for publication) revealed the presence of AZAs in one of the crude cultures. A small dinoflagellate was subsequently isolated from that well and brought into unialgal culture. A detailed taxonomic description of this dinoflagellate is in progress (Tillmann et al. in preparation). Azaspiracid production by this isolate has subsequently been confirmed by toxin measurements by LC-MS-MS of various subcultures in the laboratory.

In conclusion, without access to the near real-time data provided by such an advanced instrument at sea, we would not have been able to accomplish many objectives of the cruise - including mapping the biogeographical distribution of phycotoxins in the water column and tracing the movement of phycotoxins through the lower levels of the food web from natural samples and on-board grazing experiments. Except when occasionally present as highly concentrated blooms, toxigenic microalgae and hence their toxins are usually present at low ambient levels. The high sensitivity of the LC-MS-MS system enabled the detection and quantification of a wide variety of phycotoxins present in seawater samples containing only a few toxic cells per litre. Finally, the use of LC-MS-MS on board enabled the guided isolation, culture, and identification of the causative organism of AZP from field samples and the measurement of AZAs in various plankton fractions containing putative vector organisms for these toxins.
Acknowledgements The authors thank Philipp Hess, Marine Institute, Galway, Ireland, for the supply of an AZA-1 standard and AZAcontaining mussel reference material, and Anja These, Federal Institute for Risk Assessment (BfR), Berlin, Germany for AZA LC-MS method details. Technical assistance in the oceanographic sampling was provided by Kai Fiand and Ruben Neuhaus under the direction of Optimare AG. We also thank Captain Hansen and the entire FS Poseidon crew for their technical support and excellent collaboration throughout the entire cruise, along with the help of several AWI graduate students. This cruise was endorsed by the SCOR-IOC Programme GEOHAB as a contribution to the Core Research Project on Harmful Algal Blooms in Fjords and Coastal Embayments. Financial support was provided by the MARCOPOLI research programme of the Alfred Wegener Institute as part of the Helmholz Foundation initiative in Earth and Environment.

\section{References}

1. Hummert C, Rühl A, Reinhardt K, Gerdts G, Luckas B (2002) Chromatographia 55:673-680

2. McMahon T, Silke J (1996) Harmful Algae News 14:2

3. Satake M, Ofuji K, Naoki H, James KJ, Furey A, McMahon T, Silke J, Yasumoto T (1998) J Am Chem Soc 120:9967-9968

4. Rehmann N, Hess P, Quilliam MA (2008) Rapid Commun Mass Spectrom 22:549-558

5. James KJ, Furey A, Lehane M, Ramstad H, Aune T, Hovgaard P, Morris S, Higman W, Satake M, Yasumoto T (2002) Toxicon 40:909-915

6. James KJ, Furey A, Satake M, Yasumoto T (2000) Azaspiracid poisoning (AZP): A new shellfish toxic syndrome in Europe. In: Hallegraeff GM, Blackburn SI, Bolch CJS, Lewis RJ (eds) Harmful algal blooms 2000. IOC of UNESCO, Paris, pp 250-253

7. James KJ, Moroney C, Roden C, Satake M, Yasumoto T, Lehane M, Furey A (2003) Toxicon 41:145-151

8. Cembella AD (2003) Phycologia 42:420-447

9. Moran S, Silke J, Cusack C, Hess P (2007) Correlations between known toxic phytoplankton species and toxin levels in shellfish in Irish waters 2002-2006. In: Proc Int Conf Molluscan Shellfish Safety, Blenheim, New Zealand, in press

10. Fritz L, Quilliam MA, Wright JLC, Beale AM, Work TM (1992) J Phycol 28:439-442

11. Seki T, Satake M, MacKenzie L, Kaspar HF, Yasumoto T (1995) Tetrahedron Lett 36:7093-7096

12. Mallat E, Krock B, Fernández-Tejedor M, Caillaud A, Cañete E, Elandaloussi L, Franco J, Cembella AD, Diogène J (2007) First approach towards the implementation of passive sampling adsorption devices fort the identification of lipophilic toxins in the shellfish monitoring program in the coastal embayments of the Ebro Delta. In: Proc Int Conf Molluscan Shellfish Safety, Blenheim, New Zealand, in press

13. Hu T, Burton IW, Cembella AD, Curtis JM, Quilliam MA, Walter JA, Wright JLC (2001) J Nat Prod 64:308-312

14. Aasen JAB, MacKinnon S, LeBlanc P, Walter JA, Hovgaard P, Aune T, Quilliam MA (2005) Chem Res Toxicol 18:509-515

15. Yasumoto T, Murata M, Oshima Y, Sano M, Matsumoto GK, Clardy J (1985) Tetrahedron 41:1019-1025

16. Suzuki T, Mitsuya T, Matsubara H, Yamasaki M (1998) J Chromatogr A 815:155-160

17. Lee J-S, Igarashi T, Fraga S, Dahl E, Hovgaard P, Yasumoto T (1989) J Appl Phycol 1:147-152 